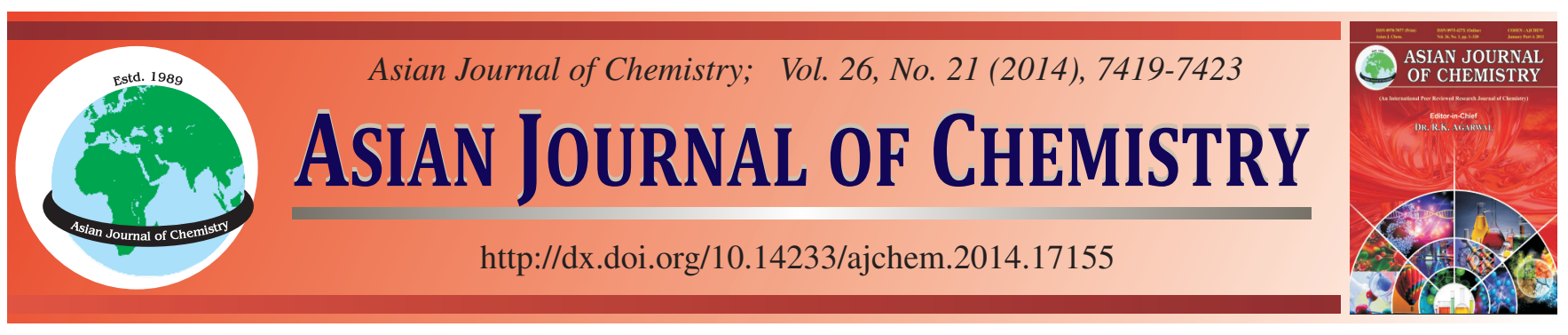

\title{
Microwave Assisted Synthesis of Barium Titanate Nanoparticles and Its Effects on the Proliferation of Primary Osteoblasts in vitro
}

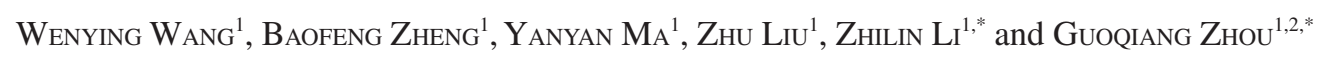

${ }^{1}$ College of Chemistry and Environmental Science, Hebei University, Baoding, P.R. China

${ }^{2}$ Key Laboratory of Chemical Biology of Hebei Province, Hebei University, Baoding, P.R. China

*Corresponding authors: Tel: +86 13731282212; E-mail: zhougq1982@163.com

Accepted: 29 April 2014;

Published online: 30 September 2014;

AJC-16152

\begin{abstract}
The barium titanate nanoparticles were successfully synthesized using microwave synthesis method and evaluated for antiproliferation activity against primary osteoblasts. The effects of microwave irradiation power and reaction time on the reaction rate and size control of barium titanate nanoparticles were investigated. The data revealed that the nanoparticle size decreasesd with increasing irradiation power. The barium titanate nanoparticles were formed after $20 \mathrm{~min}$ of microwave irradiation. The barium titanate nanoparticles synthesized were analyzed by field emission scanning electron microscopy, powder X-ray diffraction, Fourier transform infrared spectroscopy and dynamic light scattering. The barium titanate nanoparticles were nearly spherical particles with an average size of 80-100 nm. The antiproliferation activity of barium titanate nanoparticles showed that the inhibition effects followed dose and time dependent manner. The inhibition effects were increased with decreasing size and the effects may be related to cell apoptosis mechanism.
\end{abstract}

Keywords: Barium Titanate, Nanoparticles, Microwave Synthesis, Osteoblasts.

\section{INTRODUCTION}

Barium titanate $\left(\mathrm{BaTiO}_{3}\right)$, which has properties of high dielectric constant and excellent ferroelectric response, is a kind of ceramic materials based on perovskite structure ${ }^{1,2}$. Due to its characteristics, $\mathrm{BaTiO}_{3}$ has been widely used in various electroceramic areas, including thermistors, electro-optical devices, dynamic random access memories and multilayer ceramic capacitors (MLCCs) ( $^{3-6}$. With the current development trend of the miniaturization of electronic devices with improved properties and high reliability, nanoscale $\mathrm{BaTiO}_{3}$ materials are desirable ${ }^{7}$. Multilayer ceramic capacitors have larger electric capacity, can be obtained by decreasing the thickness of the ceramic layer with a decrease of the particle size ${ }^{8}$. This requires reduction in $\mathrm{BaTiO}_{3}$ particle size to nanoscale dimensions. With the novel properties of high specific surface area, volume/surface ratio and surface tailorability, $\mathrm{BaTiO}_{3}$ nanoparticles have broad application prospects in industrial and biological fields ${ }^{9,10}$.

The traditional preparation method of $\mathrm{BaTiO}_{3}$ powder is the solid-state reaction ${ }^{11}$. Conventional solid-state synthesis can yield larger quantities, but it is difficult to achieve a narrow particle size distribution when the particle sizes are less than $100 \mathrm{~nm}$. It also has high reaction temperature, poor reactivity, particle aggregation, broad size distribution and other disadvantages ${ }^{12,13}$. Microwave radiation technology is widely used to prepare high purity nanoparticles with narrow particle size distributions. Microwave heating has been known since the early 1940s and has been used in preparative chemistry and material synthesis since $1986^{14}$. Compared with the traditional heating method, microwave heating is an internal heat method which has unique features such as fast and uniform heating, no temperature gradient, short reaction time and high reaction rate ${ }^{15}$. This is beneficial to the formation of uniform nanoscale materials.

In this article, we report the preparation of $\mathrm{BaTiO}_{3}$ nanoparticles via microwave irradiation method and examine the influence of microwave power, reaction time on the size control of $\mathrm{BaTiO}_{3}$ nanoparticles. The synthesized $\mathrm{BaTiO}_{3}$ nanoparticles were characterized using X-ray diffraction (XRD), field emission scanning electron microscopy (FE-SEM), Fourier transform infrared spectroscopy (FTIR) and dynamic light scattering (DLS). The results showed that the particle size could be tuned simply by adjusting the experimental parameters. The antiproliferation effects of $\mathrm{BaTiO}_{3}$ nanoparticles on primary osteoblasts (OBs) were investigated. The results indicated that $\mathrm{BaTiO}_{3}$ nanoparticles inhibited the proliferation of osteoblasts following dose and time dependent manner and the inhibition effects may be related to cell apoptosis mechanism. 


\section{EXPERIMENTAL}

All the chemicals used in this experiment were analytical grade materials and used without further purification. Titanium tetrachloride $\left(\mathrm{TiCl}_{4}, 99 \%\right)$, barium hydroxide octahydrate $\left[\mathrm{Ba}(\mathrm{OH})_{2} \cdot 8 \mathrm{H}_{2} \mathrm{O}, 98 \%\right]$ and ammonia solution $\left(\mathrm{NH}_{3} \cdot \mathrm{H}_{2} \mathrm{O}, 25-\right.$ $28 \%$ ) were obtained from Aladdin Chemical Reagent. Deionized water was used throughout the reactions. All glasswares were washed with dilute nitric acid and distilled water, then dried in hot air oven.

Synthesis of $\mathrm{BaTiO}_{3}$ nanoparticles: The $\mathrm{BaTiO}_{3}$ nanoparticles were synthesized as following process. $11 \mathrm{~mL}$ of TiCl $_{4}$ was mixed with $20 \mathrm{~mL}$ deionized water, after hydrolysis the $\mathrm{pH}$ value of the solution was adjusted to 7 with $\mathrm{NH}_{3} \cdot \mathrm{H}_{2} \mathrm{O}$. $56 \mathrm{~g}$ of $\mathrm{Ba}(\mathrm{OH})_{2} \cdot 8 \mathrm{H}_{2} \mathrm{O}$ was dissolved in $200 \mathrm{~mL}$ of preheated deionized water to prepare clear $\mathrm{Ba}(\mathrm{OH})_{2}$ solution in parallel. The $\mathrm{Ba}(\mathrm{OH})_{2}$ solution was then added to the hydrolyzed solution mixture. The final suspension was transferred into a $200 \mathrm{~mL}$ beaker and heat-treated at 400 and $800 \mathrm{~W}$ powers in a microwave oven (Galanz $800 \mathrm{~W}$ ) for different time periods. After the reaction, the resultant product was separated by centrifugation (3000 rpm, $5 \mathrm{~min}$ ) and washed repeatedly using water and anhydrous ethanol. Then the wet precipitate dried at $100{ }^{\circ} \mathrm{C}$ in an oven for $4 \mathrm{~h}$.

$\mathrm{XRD}$ was performed on an X-ray diffractometer employing $\mathrm{CuK}_{\alpha}$ radiation with $40 \mathrm{kV}$ and $50 \mathrm{~mA}$ (D8 Advance, Bruker, Germany). The typical bonds were detected by fourier transform infrared spectroscopy (Nicolet380, Thermo, USA). The FTIR spectra obtained using the improved $\mathrm{KBr}$ pellet method by grinding down the resin beads prior to recording. The morphology and size of synthesized $\mathrm{BaTiO}_{3}$ nanoparticles were measured by FE-SEM (JSM-7500F, JEOL, Japan). A minute drop of nanoparticles solution was cast on to a carboncoated copper grid and subsequently drying in air before transferring it to the microscope. The size distribution of the nanoparticles in medium was evaluated by dynamic light scattering method (Delsa Nano C, Beckman, USA). Data were analyzed based on six replicated tests.

Isolation and culture of primary osteoblasts: The primary osteoblasts were prepared mechanically from 3-day-old Kunming mouse calvarias following the sequential enzymatic digestion method as described ${ }^{16}$. Briefly, the skulls were dissected and then, the endosteum and periosteum were stripped off and the bone was cut into approximately $1-2 \mathrm{~mm}^{2}$ pieces and sequentially digested with trypsin $(2.5 \mathrm{mg} / \mathrm{mL})$ for $0.5 \mathrm{~h}$ and collagenase II $(1 \mathrm{mg} / \mathrm{mL})$ twice for $1 \mathrm{~h}$ each time. The cells were collected and cultured in DMEM with $10 \%$ heat-inactivated fetal bovine serum, benzylpenicillin $(50 \mathrm{U} / \mathrm{mL})$ and streptomycin $(50 \mu \mathrm{g} / \mathrm{mL})$ for $24 \mathrm{~h}$ in a humidified atmosphere of $5 \% \mathrm{CO}_{2}$ in air at $37^{\circ} \mathrm{C}$ (Sanyo, Model MCO-18AIC, Japan). The culture medium was changed every 3 days during the experiments.

Cell proliferation assay: The proliferation of osteoblasts was measured according to the MTT method. In brief, osteoblasts were seeded in 96-well culture plates at a density of $2 \times 10^{4}$ cells/well and incubated for 24 or $48 \mathrm{~h}$. After incubation, $\mathrm{BaTiO}_{3}$ nanoparticles were added to the wells at concentrations of 5, 10, 20, 40 and $80 \mu \mathrm{g} / \mathrm{mL}$. Cells without $\mathrm{BaTiO}_{3}$ nanoparticles treatment were used as control group. After $24 \mathrm{~h}$ of treatment, MTT dye solution $(20 \mu \mathrm{L}, 5 \mathrm{mg} / \mathrm{mL})$ was added to each cell. Cells were further incubated for anthor $4 \mathrm{~h}$ and then analyzed using a microplate spectrophotometer (BioRad Model 3550, USA) at $570 \mathrm{~nm}$. The proliferation rate (\%) was calculated according to the formula: $\mathrm{OD}_{\text {sample }} / \mathrm{OD}_{\text {control }} \times 100$.

Analysis of apoptotic cells: The double staining assay with annexin V-FITC and propidium iodide (PI) was used to analyze the apoptotic and necrotic cells ${ }^{17}$. osteoblasts were cultured with $20 \mu \mathrm{g} / \mathrm{mL} \mathrm{BaTiO}_{3}$ nanoparticles for $24 \mathrm{~h}$. After that, cells were collected, washed in cold phosphate-buffered saline (PBS) and incubated in the dark for $15 \mathrm{~min}$ at room temperature in $100 \mu \mathrm{L}$ binding buffer containing Annexin VFITC $(40 \mu \mathrm{L} / \mathrm{mL})$ and propidium iodide $(100 \mu \mathrm{g} / \mathrm{mL})$. After incubation, $500 \mu \mathrm{L}$ binding buffer was added to each sample. The results were immediately analyzed by BD FACSCalibur flow cell cytometry (BD Bioscience, FACS Calibur, USA). Standard compensation was done in the cell quest software using single-stained and unstained cells. The percentage of early apoptotic (Annexin V+, PI-), late apoptotic and necrotic (Annexin V+, PI+) cells was determined using BD Cell Quest Pro software. Data represent the mean fluorescence obtained from a population of 10, 000 cells.

Statistical analysis: Data were expressed as mean \pm standard deviation (S.D) from three independent experiments. The statistical differences were analyzed by one-tailed unpaired Student's t-test. $\mathrm{P}$ values less than 0.05 were regarded as indicating statistical differences.

\section{RESULTS AND DISCUSSION}

Effect of microwave power: The phase composition and structure of obtained samples at different microwave power were examined by XRD (Fig. 1). The reaction time was $40 \mathrm{~min}$. All diffraction peaks can be indexed to the cubic perovskite structure which belonging to space group Pm3m (JCPDS Card No. 01-074-1968). No other byproducts can be detected. The intensity of diffraction peaks increased along with increasing irradiation power. This indicated that crystalline phase developed more complete at higher microwave power. Meanwhile, when the irradiation power increased, the width of diffraction peaks increased slightly. This indicated that the particle size decreasesd slightly along with increasing irradiation power. The above results were also in accordance with the SEM observation (Fig. 4b and 4d).

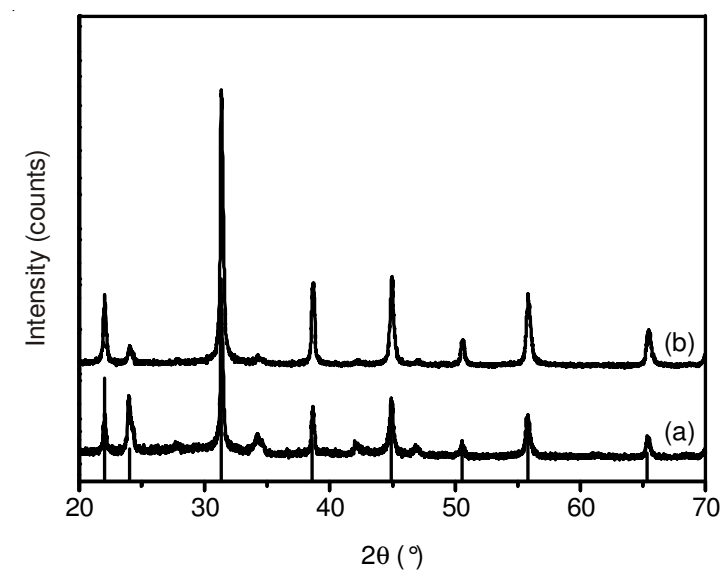

Fig. 1. XRD patterns of product obtained at different microwave power. (a) $400 \mathrm{~W}$ (b) $800 \mathrm{~W}$ 
FTIR analysis: The FTIR spectra of the synthesized $\mathrm{BaTiO}_{3}$ nanoparticles were shown in Fig. 2. The absorption peak at $580 \mathrm{~cm}^{-1}$ corresponds to the Ti-O $\mathrm{O}_{6}$ octahedral stretching vibration absorption of perovskite structure. The emergence of the absorption peak of the perovskite structure shows that $\mathrm{BaTiO}_{3}$ nanoparticles have been formed. The wide absorption band at 3500-3300 and $1630 \mathrm{~cm}^{-1}$ corresponded to the $\mathrm{OH}^{-}$on the surface of the $\mathrm{BaTiO}_{3}$ crystal. It may be due to water adsorption of the $\mathrm{BaTiO}_{3}$ nanoparticles surface. The very weak absorption peak at $1444 \mathrm{~cm}^{-1}$ corresponded to $\mathrm{CO}_{3}{ }^{2-}$ absorption peak. This suggested that a small amount of barium carbonate was present in the synthesized sample. The trace of $\mathrm{BaCO}_{3}$ is due to $\mathrm{CO}_{2}$ in the air and deionized water.

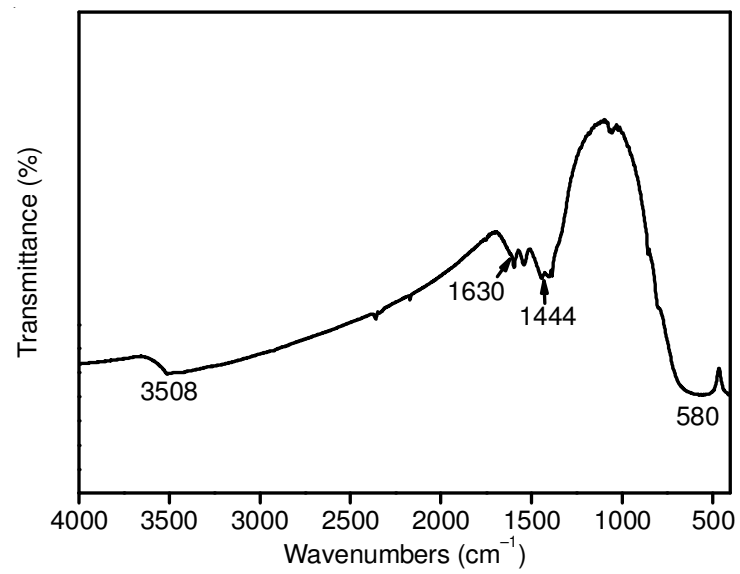

Fig. 2. FTIR spectra of sample synthesized by microwave synthesis method

Effect of reaction time: XRD spectra of the $\mathrm{BaTiO}_{3}$ nanoparticles prepared at different reaction time were shown in Fig. 3. The microwave power was $800 \mathrm{~W}$. The $\mathrm{BaTiO}_{3}$ nanoparticles were formed after $20 \mathrm{~min}$ of microwave irradiation (Fig. 3a). The corresponding SEM micrograph showed that $\mathrm{BaTiO}_{3}$ nanoparticles were almost spherical and particle size was about $80 \mathrm{~nm}$ (Fig. 4c). The intensity and width of XRD diffraction peaks have no obvious change with extension of microwave irradiation time. This indicated that the particle size remains constant with different reaction times. It may be due to the nucleation and crystallization rate can be greatly accelerated by microwave irradiation method. The precursors have been converted to $\mathrm{BaTiO}_{3}$ when the reaction time was 20 min. So the particle size would not change obviously with the extension of reaction time. The above results were also in accordance with the SEM observation (Fig. 4c and 4d). Particle size estimated by XRD was shown in Table-1. The $\mathrm{BaTiO}_{3}$ average crystallite size was calculated using Scherrer equation $\left(\mathrm{R}=0.9 \lambda / \mathrm{B} \cos \theta_{\mathrm{B}}\right)$, where $\mathrm{R}$ is the average particle size $(\AA), \mathrm{B}$ is the width of the peak at half the peak height (radians), $\lambda$ is the X-ray wavelength $(\mathrm{nm})$ and $\theta_{\mathrm{B}}$ is the Bragg angle $\left({ }^{\circ}\right)$.

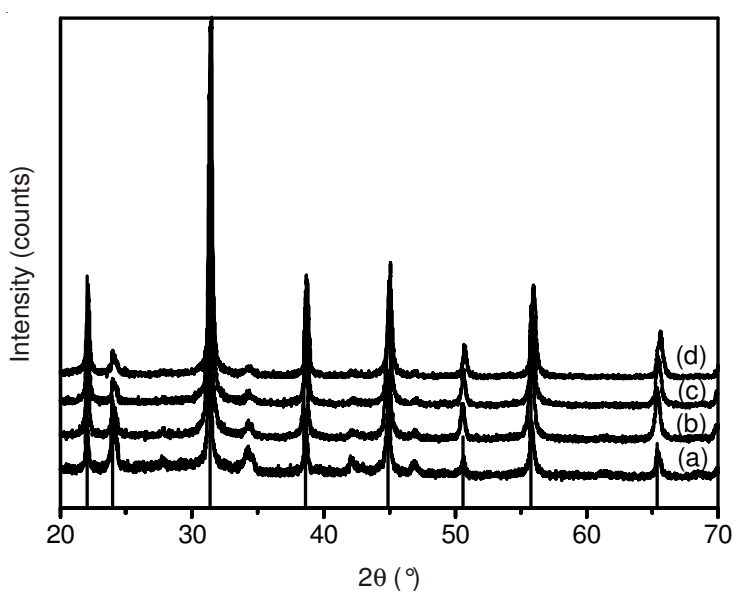

Fig. 3. XRD patterns of product obtained from different reaction times. (a) $20 \mathrm{~min} \mathrm{(b)} 40 \mathrm{~min}$ (c) $60 \mathrm{~min}$ (d) $80 \mathrm{~min}$

Dynamic light scattering analysis: The SEM images provided information on the primary size of nanoparticles. However, it could not provide information on whether the nanoparticles existed in single or aggregated forms in the culture medium. The size distribution in the culture medium, therefore, was investigated using a DLS method, which showed that the average size of $\mathrm{BaTiO}_{3}$ nanoparticles in the culture medium were $96.5 \pm 14.3 \mathrm{~nm}$ and $82.6 \pm 13.5 \mathrm{~nm}$, respectively (Fig. 5). The DLS analysis showed that the $\mathrm{BaTiO}_{3}$ nanoparticles were homogeneously dispersed in culture medium. The fluid dynamics size of $\mathrm{BaTiO}_{3}$ nanoparticles which measured by DLS was in agreement with the primary size obtained by SEM.

Osteoblast proliferation assay: As shown in Fig. 6, $\mathrm{BaTiO}_{3}$ nanoparticles inhibited the proliferation of osteoblasts following dose and time dependent manner. After osteoblasts were exposed to $\mathrm{BaTiO}_{3}$ nanoparticles $(80 \mathrm{~nm})$ at 10, 20, 40 and $80 \mu \mathrm{g} / \mathrm{mL}$ for $24 \mathrm{~h}$, cell viability decreased to $88.4,80.6$, 70.6 and $50.3 \%$, respectively, compared to the control. The inhibitory effects of $80 \mathrm{~nm}$ nanoparticles were higher than that of $95 \mathrm{~nm}$ nanoparticles. After osteoblasts were exposed


$24 \mathrm{~h}$, cell viability decreased to $93.2,85.9,78.3$ and $63.1 \%$, respectively, compared to the control. It is logical to state that the inhibition of $\mathrm{BaTiO}_{3}$ nanoparticles to the cells depends on the particle size. The smaller sized particles which have larger surface areas available for interactions with cells than the larger sized particles, hence they show higher cytotoxicity to cells. The inhibition effects of $\mathrm{BaTiO}_{3}$ nanoparticles on osteoblasts at $48 \mathrm{~h}$ were similar with that at $24 \mathrm{~h}$.

Cell apoptosis assay: Cell apoptosis were measured by the annexin V/propidium iodide (PI) assay. The externalization of phosphatidyl serine as a marker of early-stage apoptosis was detected by the annexin $\mathrm{V}$ protein conjugated to FITC,

TABLE-1

PARTICLE SIZE AS ESTIMATED FROM XRD AND SEM MEASUREMENTS

\begin{tabular}{ccccc}
\hline Sample & Microwave power $(\mathrm{W})$ & Reaction time $(\mathrm{min})$ & Size from XRD $(\mathrm{nm})$ & Size from SEM $(\mathrm{nm})$ \\
\hline 1 & 400 & 20 & 98 & 100 \\
2 & 400 & 40 & 93 & 95 \\
3 & 800 & 20 & 80 & 83 \\
4 & 800 & 40 & 79 & 80 \\
\hline
\end{tabular}



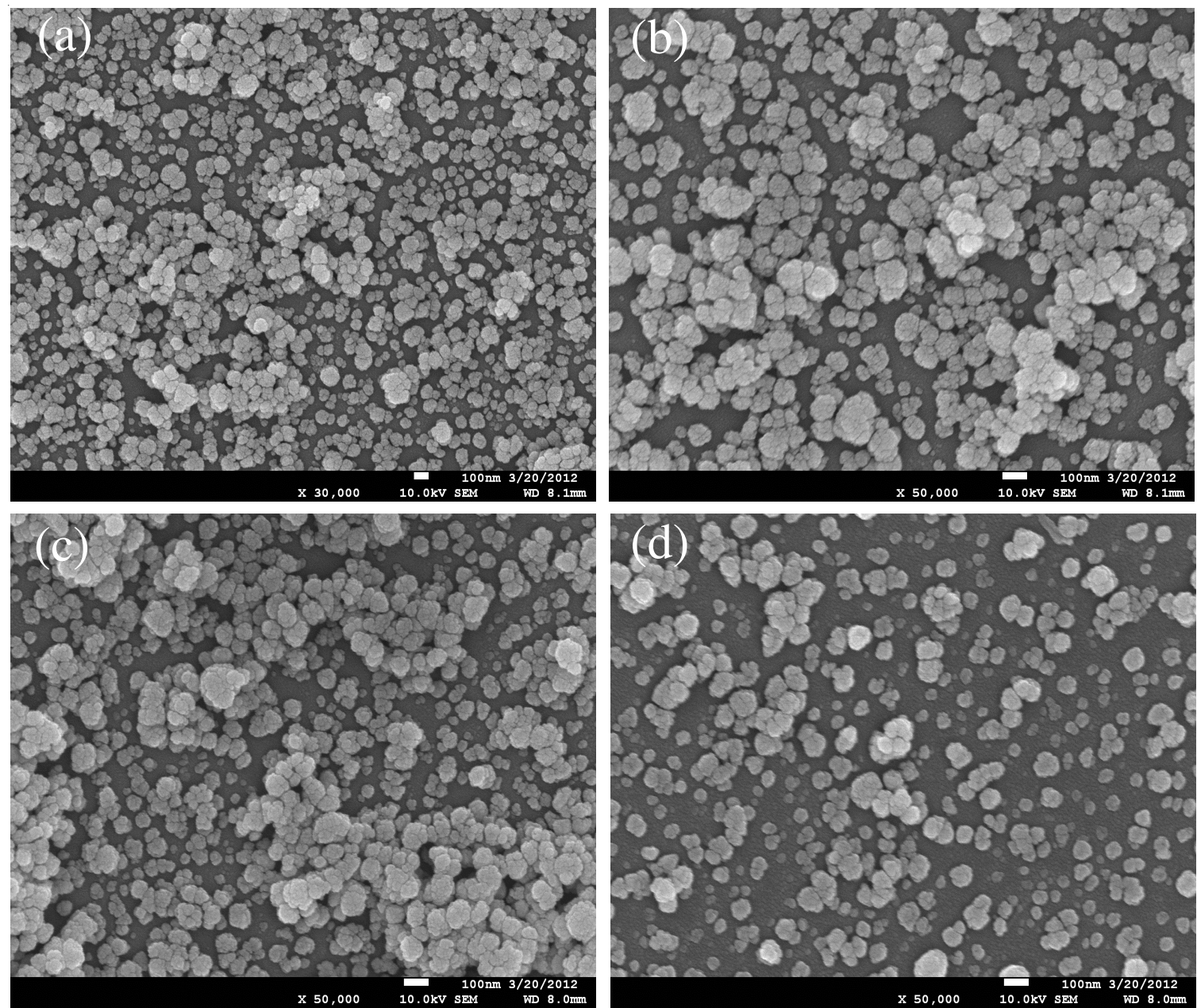

Fig. 4. SEM images of $\mathrm{BaTiO}_{3}$ nanoparticles obtained from different reaction times and microwave powers. (a) $20 \mathrm{~min}, 400 \mathrm{~W}$ (b) $40 \mathrm{~min}, 400 \mathrm{~W}$ (c) 20 min, $800 \mathrm{~W}$ (d) $40 \mathrm{~min}, 800 \mathrm{~W}$
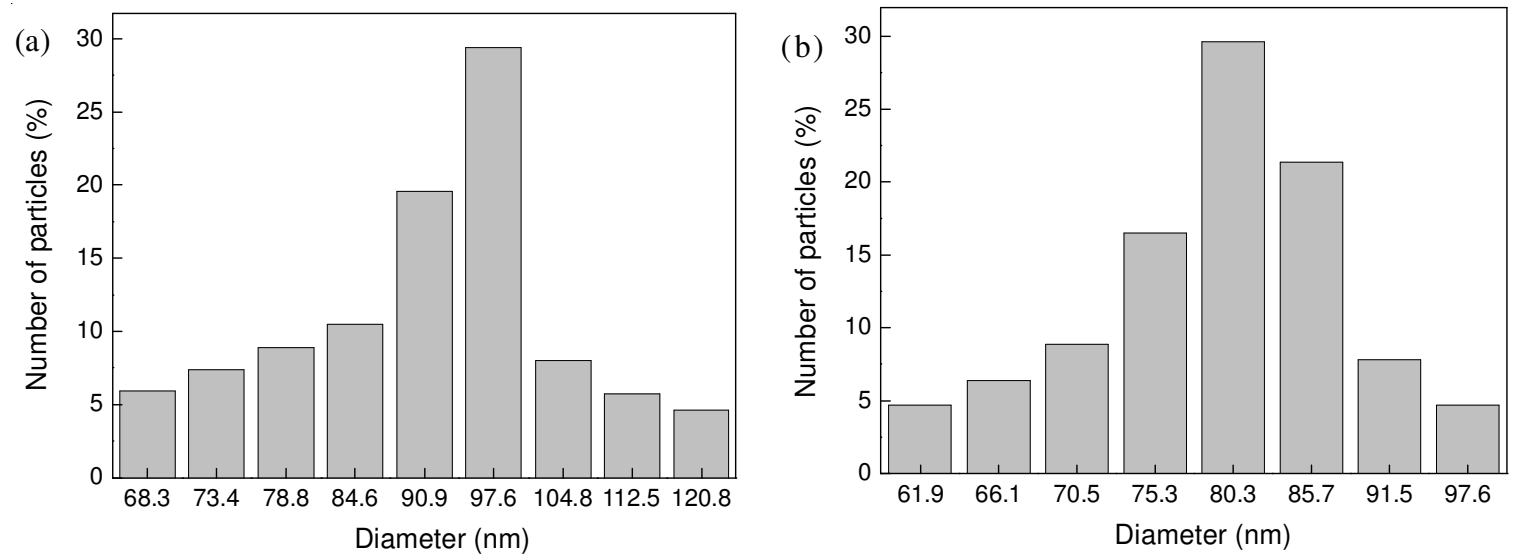

Fig. 5. Size distribution of $\mathrm{BaTiO}_{3}$ nanoparticles in medium measured by DLS. (a) $40 \mathrm{~min}, 400 \mathrm{~W}$ (b) $40 \mathrm{~min}, 800 \mathrm{~W}$

whereas membrane damage due to late-stage apoptosis/ necrosis was detected by the binding of propidium iodide to nuclear DNA. Healthy cells are double negative, early apoptotic cells are positive for annexin $\mathrm{V}$ staining but negative for PI staining, while late apoptotic cells are double positive staining. PI stained cells are necrotic ${ }^{18}$. BD Cell Quest Pro software was employed to quantify apoptotic cells in order to further confirm the effect of $\mathrm{BaTiO}_{3}$ nanoparticles on the primary osteoblasts (Fig. 7). Osteoblasts were incubated with two sized $\mathrm{BaTiO}_{3}$ nanoparticles $(95 \mathrm{~nm}$ and $80 \mathrm{~nm}$ ) at a concen- tration $20 \mu \mathrm{g} / \mathrm{mL}$ for $24 \mathrm{~h}$. After osteoblasts were exposed to $\mathrm{BaTiO}_{3}$ nanoparticles $(95 \mathrm{~nm}$ and $80 \mathrm{~nm})$ for $24 \mathrm{~h}$, the apoptotic rate of cells was $18.7 \%$ and $21.6 \%$, respectively. The apoptotic rate of control group was $4.7 \%$. Therefore, all above data clearly indicate that $20 \mu \mathrm{g} / \mathrm{mL} \mathrm{BaTiO}_{3}$ nanoparticles can induce the apoptotic of primary osteoblasts during an incubation period of at least $24 \mathrm{~h}$.

\section{Conclusion}

Quasi-spherical $\mathrm{BaTiO}_{3}$ nanoparticles were synthesized successfully using microwave irradiation method. Average size 

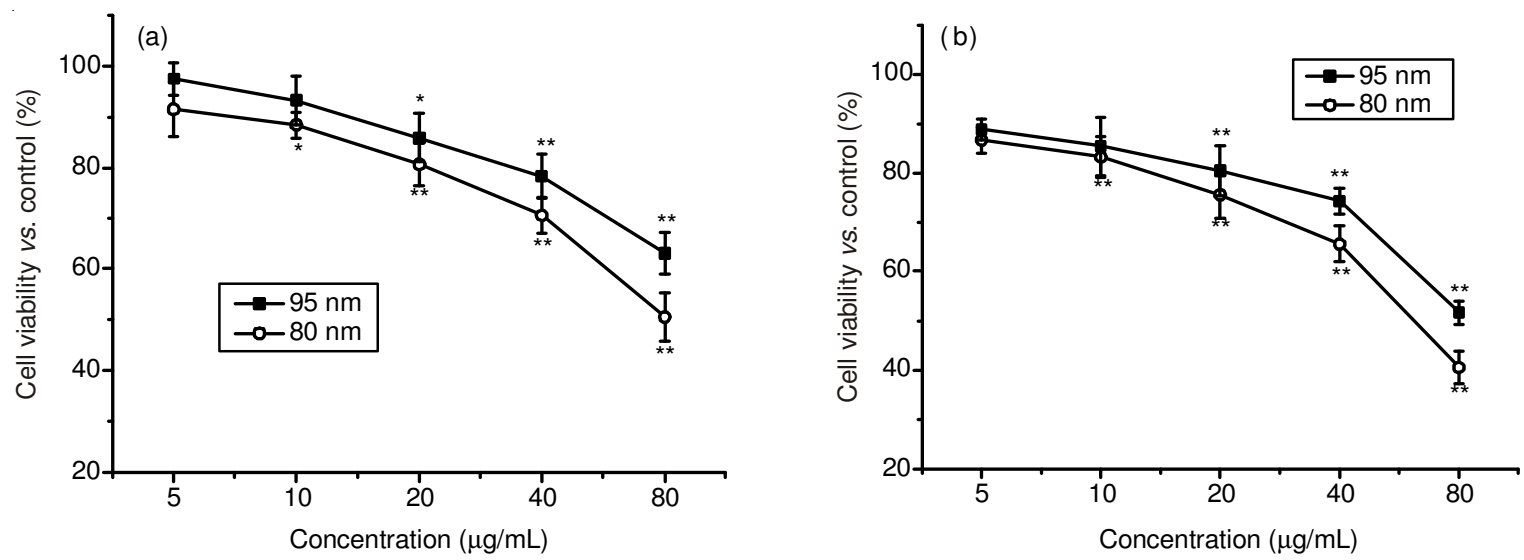

Fig. 6. Effects of $\mathrm{BaTiO}_{3}$ nanoparticles on the proliferation of primary osteoblasts. (a) $24 \mathrm{~h}$ (b) $48 \mathrm{~h}$. $(* \mathrm{P}<0.05$, $* * \mathrm{P}<0.01$ compared with the control group, $\mathrm{n}=6$ )


Fig. 7. Effects of $\mathrm{BaTiO}_{3}$ nanoparticles on the apoptosis rate of osteoblasts (a) Control group. (b) $95 \mathrm{~nm} \mathrm{BaTiO}_{3}$ nanoparticles treated group. (c) $80 \mathrm{~nm}$ $\mathrm{BaTiO}_{3}$ nanoparticles nanoparticles treated group

of the $\mathrm{BaTiO}_{3}$ nanoparticles was tunable by simply changing the microwave power and reaction time of the reactions. The results of characterization showed that the particle size decreased with increasing microwave irradiation power in the formation of $\mathrm{BaTiO}_{3}$ nanoparticles. XRD pattern showed that pure nanostructures with high crystallinity had been made. Antiproliferation activity of $\mathrm{BaTiO}_{3}$ nanoparticles revealed that the inhibition effects were similar in case of two sized $\mathrm{BaTiO}_{3}$ nanoparticles, while the smaller size nanoparticles showed slightly better antiproliferation effect. The inhibition effects followed dose and time dependent manner and this effects may be related to cell apoptosis mechanism.

\section{ACKNOWLEDGEMENTS}

This work was financially supported by the National Natural Science Foundation of China (21001038), Key Basic Research Special Foundation of Science Technology Ministry of Hebei Province (12966418D) and College Students Innovative Training Project of Hebei University (2013074).

\section{REFERENCES}

1. T. Lee and I.A. Aksay, Cryst. Growth Des., 1, 401 (2001).

2. W.J. Merz, Phys. Rev., 76, 1221 (1949).

3. A.I. Kingon, S.K. Streiffer, C. Basceri and S.R. Summerfelt, MRS Bull., 21, 46 (1996).
4. Y. Luo and X. Liu, Mater. Lett., 59, 3881 (2005).

5. M. Mori, T. Kineri, K. Kadono, T. Sakaguchi, M. Miya, H. Wakabayashi and T. Tsuchiya, J. Am. Ceram. Soc., 78, 2391 (1995).

6. P.K. Singh, S. Cochrane, W.T. Liu, K. Chen, D.B. Knorr, J.M. Borrego, E.J. Rymaszewski and T.M. Lu, Appl. Phys. Lett., 66, 3683 (1995).

7. R.D. Levi and Y. Tsur, Adv. Mater., 17, 1606 (2005).

8. X. Wei, G. Xu, Z.H. Ren, Y.G. Wang, G. Shen and G.R. Han, J. Am. Ceram. Soc., 91, 315 (2008).

9. G. Ciofani, S. Danti, S. Moscato, L. Albertazzi, D. D'Alessandro, D. Dinucci, F. Chiellini, M. Petrini and A. Menciassi, Colloids Surf. B Biointerfaces, 76, 535 (2010).

10. Z.G. Shen, J.F. Chen, H.K. Zou and J. Yun, J. Colloid Interf. Sci., 275, 158 (2004).

11. L.K. Templeton and J.A. Pask, J. Am. Ceram. Soc., 42, 212 (1959).

12. W. Maison, R. Kleeberg, R.B. Heimann and S. Phanichphant, J. Eur. Ceram. Soc., 23, 127 (2003).

13. S. Yoon, S. Baik, M.G. Kim and N. Shin, J. Am. Ceram. Soc., 89, 1816 (2006).

14. R.J. Giguere, T.L. Bray, S.M. Duncan and G. Majetich, Tetrahedron Lett., 27, 4945 (1986).

15. N. Arshi, F. Ahmed, S. Kumar, M.S. Anwar, J.Q. Lu, B.H. Koo and C.G. Lee, Curr. Appl. Phys., 11, S360 (2011).

16. G.Q. Zhou, G.Q. Gu, Y. Li, Q. Zhang, W.Y. Wang, S.X. Wang and J.C. Zhang, Biol. Trace Elem. Res., 153, 411 (2013).

17. Y. Liu, F. Jiao, Y. Qiu, W. Li, Y. Qu, C.X. Tian, Y.F. Li, R. Bai, F. Lao, Y.L. Zhao, Z.F. Chai and C.Y. Chen, Nanotechnology, 20, 415102 (2009).

18. R. Foldbjerg, D.A. Dang and H. Autrup, Arch. Toxicol., 85, 743 (2011). 